\title{
Cárceles: laberintos y cerrojos
}

\author{
Recibido 29/11/2012 - Aprobado 14/03/2013
}

Fernando Tocora López

\section{Resumen}

El presente artículo presenta una revisión y crítica del actual sistema carcelario, en particular del colombiano, a partir de la contraposición de las propuestas de justificación de la cárcel como medio de punición, con la realidad de las cárceles y una propuesta político criminal de reducción del poder penal sustentada en la filosofía política del humanismo.

\section{Abstract}

This article presents a review and critique of the current prison system, particularly the Colombian from the juxtaposition of proposed justification of prison as a means of punishment, with the reality of prisons and criminal political proposed reduction penal power sustained by the political philosophy of humanism.

\section{Palabras clave}

Justificación de la prisión, prisión, retribucionismo, resocialización, prevención general, prevención especial.

\section{Keywords}

Justification of the prison, prison, retributivism, resocialization, general prevention, special prevention.

* Doctor en derecho y ciencias políticas Universidad de Cali, Colombia. Contacto: ftocora@hotmail.com 


\section{Sumario}

1. La prisión: el dolor. 1.1. La "sobredosis de dolor". 1.2. Las condiciones mínimas del dolor, 2. El viejo mito de la resocialización. 3. La cárcel: una institución violenta.

4. El hacinamiento pestilente. 5. Regímenes disciplinarios al límite

\section{La prisión: el dolor}

Hablar del dolor, de los sentimientos, en materia de política -así sea política criminal- podría parecer inusual. Podemos hablar de control social, de infracciones legales, de debido proceso, de procesos de criminalización, y de tantos otros temas abstrusos, pero hablar de dolor, de emociones, de sentimientos, no parece ir muy de la mano del manejo científico de una disciplina social. Los seres humanos tienen que ir al sicólogo a hurtadillas o aproximarse sigilosamente al confesionario de su sacerdote, para hablar del dolor, del dolor que se sufre como víctima pero también del dolor del pecado que genera dolor en el otro, y en uno. Claro, aquel es el primer dolor, el de la víctima, y ese es un dolor que se olvidó durante mucho tiempo, por la preocupación del discurso liberal en el perseguido por el sistema penal, víctima a su vez de tanto abuso, de la Inquisición, de los déspotas. Ciertamente, como lo han señalado los abolicionistas, el Estado hurtó el conflicto a sus protagonistas, hizo a un lado a la víctima y se encargó de resolver verticalmente el antagonismo. Pero ahora, el derecho penal ha vuelto la mirada hacia las víctimas, cuyo dolor es el primero, en el tiempo y en las prioridades; Más hay otro dolor, el que trae el derecho penal. Ese dolor modernamente tiene un nombre principal: la prisión.

El castigo presupone ciertamente una aflicción. Su historia está llena de infamias: descuartizamientos, hogueras, amputaciones, torturas inimaginables, etc. Todavía hoy existen. Los Talibanes entierran a las mujeres adúlteras hasta el pecho y las apedrean hasta morir. El presidente Bush, hijo, ha reconocido que ordenó aplicar la tortura del sumergible (ahogamiento) a los presos en Guantánamo. El reemplazo de esos castigos por la prisión no significa la eliminación de los suplicios. La ergástula castiga, el espíritu y el cuerpo. Lacera, lastima, deprime. Duele el alma, duelen las entrañas, duele la piel. No se trata solamente de "privaciones" que se deriven del encierro. Se trata de verdaderos sufrimientos, cuyas evoluciones sico-somáticas se revelan en diferentes tipos de enfermedades físicas pero sobre todo síquicas, como depresiones, brotes sicóticos, paranoias, etc. Los trastornos en la identidad de la persona, a partir del etiquetamiento como criminal, constituye un verdadero trauma que remueve toda la estructura de la relación ser humano-mundo o ser humano-sociedad. El ser humano que es ser social por naturaleza, ve amenazada su relación con ese cuerpo social; se ve rechazado, expulsado, o mejor, más excluido, porque generalmente ya lo estaba cuando cayó en el delito. 
El dolor de la pena privativa de la libertad que conocemos como cárcel, se sufre no solo durante, sino antes y después. Antes, porque la amenaza de la prisión se siente muchas veces con anterioridad. El solo proceso penal, pendiendo como espada de Damocles, inquieta, angustia, produce insomnio. Si se tiene orden de captura se eleva el nivel de la ansiedad, la libertad queda restringida y se empieza a sufrir los rigores de esa restricción. En ambas situaciones, el estigma ya está sobre nosotros y empezamos a padecer el proceso de una ruptura social. El sufrimiento posterior de la prisión, nos lo proporciona no solamente la memoria del castigo, sino las secuelas de ese encierro, físicas, sicológicas; pero también, cuando la sociedad, que suele tomar distancia de los condenados, los rechaza para un empleo, obtener una visa, un crédito, o cuando se le sigue reprochando su culpa.

Del relevo que la prisión hizo de los castigos corporales, nos habla Christie:

La tasa de cambio para la transición de entre la tortura física y la pérdida de la libertad fue establecida por una ley del 15 de octubre de 1815: 'En lugar de la pérdida de una mano, reclusión de 10 años; en vez de horadar y arrancar una mano, reclusión de dos años, y en vez de horadar una mano, reclusión por un año 1 .

La anterior es una ley sueca, que ilustra bien sobre la posibilidad de conversión de una pena en otra. Si bien, son diferentes, guardan el hilo conductor del dolor.

Cuando la modernidad instauró esta pena como la pena por antonomasia del nuevo Estado de Derecho, la ponderó como pena abstracta e igual. No se trataba de una pena-vindicta 0 de una pena según la ley del talión, que determinaban la medida y la naturaleza de la reacción según la del derecho conculcado. Se trataba de una pena general y abstracta, que si bien tenía que tener en cuenta el delito que la generaba, para efectos de la proporcionalidad de la pena siguiendo la jerarquía de los bienes jurídicos protegidos, era una pena homologada en su contenido: el encierro, la privación de la libertad. Frente al abanico de penas imperantes en la premodernidad -torturas, pena de muerte, amputaciones, destierro, galeras, trabajos forzados, penas pecuniarias, privativas de derechos, etc.-, la prisión se alza en la modernidad como la pena protagónica, principal, casi única del sistema penal.

Es en el siglo XIX cuando la cárcel se convierte en la principal de las penas, reivindica por un lado la igualdad, de cara a la aplicación de penas diversas como las señaladas, que no permiten un factor de conversión que garantice igualdad en la adjudicación de la punición, teniendo en cuenta desde luego que esa igualdad se da en la proporcionalidad entre crimen y castigo. Del otro lado, alega su humanidad, en cuanto supera todo ese pasado de penas infamantes, torturas, penas de muerte ejecutadas con la mayor barbarie, amputaciones, galeras, trabajos forzados, últimas

1 Niıs Christie, La industria del control del delito, Buenos Aires, Editores del Puerto s.r.l., 1993, p. 35. 
dos estas, que eran consideradas por algunos como penas de muerte lenta al agotar hasta la extenuación a los condenados.

Ni lo uno ni lo otro, ha sido honrado por la nueva pena. Ni la igualdad, porque la historia nos ha demostrado cuan selectiva ha sido, ni la humanidad, porque también a partir de esa experiencia se ha revelado como violenta y cruel. Básicamente la pena de prisión ha sido adjudicada a la delincuencia convencional, con el rigor que Víctor Hugo expone magistralmente en "Los Miserables". Ha sido una pena altamente selectiva en la escogencia de su "clientela", empecinada en llevar a los desposeídos a su hábitat amurallado. Y luego ha sido una pena cargada de violencia y oprobio, con los niveles de vejación y de inhumanidad como lo ha narrado una película descollante del cine latinoamericano, que lleva el nombre de la cárcel más grande de todo el subcontinente: Carandiru (Sao Paulo).

\subsection{La "sobredosis de dolor"}

Aquí hay que apuntar a la cantidad de dolor, que no es la que se imaginaron los que la instauraron, ni la que conciben los legisladores al momento de determinar primariamente la duración de la pena, sino un castigo muy superior. Si bien pregonaron que era una pena cuantificable y mensurable, no se anticiparon a pensar el nivel de degradación que sufriría pasando del papel a la práctica. En realidad la pena que se ejecuta es una pena mucho más infamante y dolorosa que la pena que prevén los códigos. Una es la pena escrita en el papel, destinada a la resocialización o cuando menos a una retribución humanizada, y otra es la pena viva que se ejecuta entre muros de silencio y arbitrariedad. Cuando se debate una ley penal que crea o aumenta penas, no se pone generalmente en consideración la ferocidad de su ejecución. Se supone que son tiempos de encierro digno y hasta algunos hablan en términos de hotelería: comida y cama para unos que han atentado contra la sociedad, pero no aceptan, porque en su autoritarismo no quieren ver, que además de cama y comida, las cárceles están cargadas de violencia, violencia oficial, violencia de los mismos presos entre ellos, violencia como aire que se respira, violencia del hacinamiento fétido, violencia de regímenes disciplinarios draconianos. Este panorama multiplica el castigo. Lo dispara por fuera de las proporciones que el derecho y la política criminal le traza. El castigo es varias veces superior. La dosis de dolor es mayor que la de la ecuación delito = pena. Finalmente es una sobredosis.

Si las cárceles cumplieran los mínimos requerimientos de la decencia y de respeto a la dignidad humana, las penas que en ellas se ejecutaran corresponderían a las previstas en los códigos penales. Pero cuando la realidad es otra muy diferente, cruel e inhumana, no solamente se constituye "un estado de cosas inconstitucional"2 
sino que las penas superan la magnitud del castigo que debieran tener, por cuanto la "dosis de dolor" es superior. Esto deviene en injusticia, en arbitrariedad y prepara el terreno para más violencia, más crimen, más dolor.

Cuando el legislador prevé una escala penal, lo hace sobre un supuesto de penalidad en la que se respeta la dignidad humana del castigado; sobre esa base el legislador opta por un mínimo y un máximo penal como las medidas límite del castigo entre las cuales se deberá mover el juez, con lo cual queda a salvo el principio de legalidad de las penas. Pero cuando la base fáctica de la aplicación de la norma cambia sustancialmente, convirtiéndose el castigo en una intensiva y cruel laceración del cuerpo y del espíritu, que mengua sensiblemente las condiciones orgánicas y horada la integridad síquica del sujeto prisionalizado -quien ve disuelta su autoestima personal y afrentada irreversiblemente su dignidad humana-, la pena se multiplica varias veces, recibiendo el condenado una pena muy superior a la concebida y prevista por el legislador. Con ello se viola el axioma de legalidad de las penas, en la medida en que hay un excedente de castigo, siendo la aplicación cruel, inhumana y degradante. En otras palabras, si fuera posible establecer una "medida de dolor", el penado resulta purgando más unidades de las que la ley previó e incluso de las que el juez quiso imponer.

\subsection{Las condiciones mínimas del dolor}

En la mayoría de las cárceles latinoamericanas no se cumplen las “Reglas mínimas para el tratamiento de los reclusos", aprobadas en Ginebra 1955. Concretamente no se cumplen las condiciones de higiene, superficie mínima, celdas individuales, instalaciones sanitarias adecuadas, programas de ayuda al postpenado. Otras puede que se incumplan un poco menos, pero todavía sigue siendo una mayoría las que no se cumplen, como la de alimentación de buena calidad, existencia de bibliotecas, oportunidades laborales y de educación, visitas familiares decorosas, supervisión médica del sancionado disciplinariamente, sanciones disciplinarias cuya drasticidad hace temer por un desenlace fatal. Pero más allá de esas reglas que reiteramos son las mínimas ${ }^{3}$, hay que censurar que las prisiones no garanticen la vida, ni la integridad

cosas inconstitucional" en el sistema de prisiones en Colombia, razón por la cual concedió al Estado colombiano un plazo de cuatro años para corregirlo, sin que tal estado de cosas haya cambiado sustancialmente 8 años después del vencimiento del término, al respecto véase la Sentencia T-153 de 1998, de la Corte Constitucional colombiana.

3 A aquel instrumento internacional se suman los Principios básicos para el tratamiento de los reclusos (Naciones Unidas 1990), Las Reglas de las Naciones Unidas para la protección de los menores privados de libertad (Naciones Unidas 1990), el Protocolo de Estambul o Manual para la investigación y documentación eficaces de la tortura y otros tratos o penas crueles, inhumanos 0 degradantes (Naciones Unidas 2001). Para el caso de América Latina, se incumple "Los Principios y Buenas Prácticas sobre la Protección de las Personas Privadas de la Libertad en las Américas" (Comisión Interamericana 
personal y sexual de los presos, y en general que el "estado de cosas" afrente la dignidad humana de los reclusos.

La sentencia de la Corte Constitucional colombiana que declaró el "estado de cosas inconstitucional"4 certificó todos aquellos males como concurrentes en el sistema penitenciario de Colombia, agregando el incumplimiento de las obligaciones de clasificación de los internos, hallando que se encontraban mezclados los primíparos y los reincidentes, los miembros de la fuerza pública, los funcionarios públicos y los indígenas con todos los prisioneros restantes. La Corte ordenó que dada la magnitud y el carácter estructural de la situación, se corrigieran las falencias anotadas en el término de cuatro años. Transcurrido dicho lapso la inconstitucionalidad continua, no obstante la construcción de varios grandes centros penitenciarios; el problema no solamente es de espacio físico, sino de superpoblación carcelaria en tal magnitud que siempre va adelante de las actualizaciones arquitectónicas; también es un fenómeno de mentalidad meramente retributiva y vindicativa de la administración y los guardias, de proyección de la realidad corrupta y violenta del país en esa maqueta de él que es la cárcel, de falta de presupuesto adecuado para otros requerimientos institucionales (asistencia médica, alimentación, programas de educación, trabajo, etc.). Sobre esto hablaremos más adelante con sentido propositivo.

No obstante, en medio de ese panorama general, existen presos privilegiados que pueden tener celdas independientes, condiciones decorosas de reclusión, y buenas posibilidades de redención de pena mediante trabajo y estudio. Es el caso de los congresistas colombianos condenados por la Corte Suprema de Justicia, por concierto para delinquir, ${ }^{5}$ cometido para garantizarse su elección o reelección en el cuerpo legislativo, a través de amenazas de muerte a pueblos y regiones enteras de sufrir consecuencias colectivas funestas de no votar por sus candidaturas. Esas amenazas se hicieron efectivas muchas veces, en sonadas masacres que la comunidad internacional conoce. Estos presos predilectos del ejecutivo -el Estado maneja las prisiones-, además de tener unas buenas condiciones de internamiento, les otorgan numerosos permisos al mes para ir al médico y al odontólogo, a citas y a exámenes médicos, que generalmente utilizan para irse de francachela con sus familiares, cómplices y escoltas. El cómodo régimen carcelario se explica en que la mayoría de esos parlamentarios, sino todos, prestaron su concurso político para la elección y

de derechos humanos 2008). El conjunto de los instrumentos jurídicos internacionales que versan sobre el tema de la prisión producidos por las Naciones Unidas es lo que se ha llamado su Modelo Penitenciario de Derechos y Obligaciones.

4 Sentencia T-153 de 1998.

5 Se refiere el caso de la llamada "parapolítica", o alianza entre paramilitares y políticos, para garantizarle a estos últimos su elección a cuerpos colegiados o cargos en el ejecutivo, de elección popular (gobernadores, alcaldes) o de nombramiento. 
la reelección del Presidente Uribe Vélez. Uno de esos políticos, Salvador Arana, fue condenado por el asesinato de un alcalde de su región, muerte anunciada por el mismo burgomaestre cuando en Consejo Comunal celebrado por la propia Presidencia de la República, denunció ante cámaras que iba a ser asesinado por el paramilitarismo y suplicaba a las autoridades gubernamentales la protección de su vida. El Alcalde fue asesinado semanas después. Arana ejercía como gobernador de su departamento y no obstante los indicios y las denuncias de su vinculación con los paramilitares y con el crimen del alcalde, fue nombrado como Embajador de Colombia en Chile.

No es que ofusque que los presos tengan celdas independientes, condiciones decorosas de encierro y posibilidades de redención de la pena; lo que descompone es la desigualdad, que para los peores crímenes, como los de las masacres, se brinde esas condiciones de privilegio, y para otros menores se impongan regímenes de ejecución penal del mayor rigor. Indigna también, que se burlen de las sentencias de los jueces y de una sociedad ultrajada. ${ }^{6}$

\section{El viejo mito de la resocialización}

El discurso de la resocialización ha demostrado toda su falacia desde el origen mismo de la prisión. La crítica que se pueda erguir contra este mito del derecho penal, no es en principio la que nos permita hacer un balance histórico de la experiencia de las prisiones, sino la que surge de la incongruencia entre sociedades que generan delitos y las políticas de reintegración a su seno, sociedades excluyentes que pretenden incluir a quienes previamente han expulsado al margen de los bienes sociales, materiales y culturales. Sociedades que han evidenciado doblez, egoísmo, falta de piedad y de solidaridad y cuyos procesos de acumulación de capital han ido muchas veces de la mano de la ilegalidad. Contradicciones que son todavía mayores cuando el modo de la pretendida reintroducción social se verifica a través de una institución aislante, estigmatizante y destructora de la personalidad. Se aspira a la inclusión a través de una institución excluyente, institución total, institución totalitaria.

Para que una sociedad pueda pretender la resocialización, debe ser una sociedad en la que se respete los derechos fundamentales de todos los asociados, una sociedad en la que existan las oportunidades de realización de los derechos básicos, cuya ausencia yace en la génesis de gran parte de la delincuencia. Cuando quienes delinquen surgen de escenarios sociales de condiciones infrahumanas estamos ante una política criminal deslegitimada. Cuando muchos de quienes caen en el delito, perciben que no hay mucha diferencia comportamental entre ellos y una buena parte de los

6 Estos hechos de salidas fraudulentas de la prisión, para realizar banquetes y juergas, fueron denunciados por el propio Ministro del Interior del nuevo gobierno de Juan Manuel Santos. 
sectores que le impone el castigo, que también viola la ley (políticos, empresarios, policías, funcionarios, etc.), la pretensión de reintegrar suena a cinismo e hipocresía. ¿Qué puede pensar un ladrón callejero cuando lee titulares de prensa sobre robos o peculados millonarios cometidos por señores de "cuello blanco", que él nunca se topa en las cárceles? ¿Qué puede pensar un marihuanero de verse lanzado violentamente a la cárcel, cuando una buena parte de la sociedad que lo condena convive y hace negocios con los grandes narcotraficantes?

Cuando la represión misma versa sobre conductas que no constituyen grave afrenta a la sociedad, o incluso no atenta contra bienes jurídicos de terceros (delitos sin víctima, delitos de peligro abstracto, delitos de mero contenido moralista, etc.), la persecución penal está por fuera del marco constitucional de sociedades que se estructuran en torno a las libertades. Otra cosa sucede en sociedades totalitarias, en las que sí desde fuera se pretende la uniformidad de los espíritus y del pensamiento, al interior de la prisión ese objetivo se torna más intenso y obcecado. En la antigua Unión Soviética el delincuente no solamente transgredía una norma penal sino también el "espíritu de la revolución socialista". La respuesta del Estado tenía por objetivo, realinear al infractor con los postulados de esa revolución, le gustara o no. No se trataba de inculcarle que había atentado contra un bien jurídico ajeno, sino que había atentado contra todo el sistema, contra toda la revolución, y tenía que enmendarse no solamente en su actitud concreta que lo llevó a la prisión, sino en toda su postura ideológica. Igual sucedió con el régimen nazi, en el que había que estar de acuerdo con el "sano sentimiento del pueblo alemán"; quien cometía una lesión personal por ejemplo, no solo atentaba contra la integridad personal de otra persona, sino que contravenía todo el credo del régimen, que le imponía velar por la "pureza de la raza", ser leal al Führer, no leer los textos prohibidos que el régimen enlistara en un índice, odiar a los judíos, etc.

Aceptando que nuestras sociedades tuvieran un índice adecuado de oportunidades, de justicia, que se aproximaran a los modelos nórdicos de bienestar, por tomar un punto de referencia real, tendríamos que aceptar de cara a las cárceles que tenemos, que las pregonadas políticas de resocialización no han sido más que palabras: discursos oficiales, ensayos y cátedras académicos, editoriales de medios de comunicación. La realidad ha ido en contravía. En la vía que continua la desocialización del individuo, su discriminación. La cárcel no ha hecho más que reproducir la marginalidad. Los efectos de la prisión han sido devastadores para quienes la han padecido. Efectos de desintegración sicológica, entre las altas tensiones de querer pertenecer y participar de los frutos de una sociedad, o las de unirse a grupos desviados donde se les da un reconocimiento. La llustración con su postura individualista confrontó la pretensión de reforma del penado. Planteó inicialmente un correccionalismo, pero cuidándose 
de intervenir invasiva y exhaustivamente en la personalidad del reo. Luego con el advenimiento del positivismo, la consigna de la resocialización se hizo "científica" a través del tratamiento en la ejecución penal, tratamiento que debía curar, redimir, reformar al reo, preparándolo para su reinserción social. Sin embargo, la constatación empírica de la ausencia de las políticas proclamadas de resocialización y las altas tasas de reincidencia se encargarían de negar la concreción de esas promesas.

En las sociedades periféricas esa política es tanto más absurda, en cuanto la mayoría de la delincuencia que guardan las prisiones, proviene generalmente de sectores miserables de la sociedad, a los cuales deben retornar, con desventajas adicionales como la de su etiquetamiento como delincuentes, su resentimiento por el generalmente desproporcionado castigo, al que se suma el de la violencia de la cárcel, ejercida tanto por los guardias como por los grupos que se crean en la prisión; también inciden contra el propósito resocializador los lazos que se forman en la sociedad carcelaria, lazos que afianzan el sentimiento de ruptura con la sociedad y de identidad como desviado, que impulsan o reimpulsan a la vez la carrera criminal.

Si se habla de resocialización, debemos comenzar por entender a cuál "socialización" pretendemos volver. Si socialización es un proceso por el cual adquirimos una identidad a través de la internalización de unas normas de cultura, y esas normas pueden variar dentro de los conglomerados sociales, cuál es la sociedad a la que revertiremos los penados: a la suya miserable, con la que encuentra una identificación, pero que los lanzara a la desviación, o a sociedades extrañas que les son ajenas pero que retienen mejores condiciones de vida, como aquella en que viven los legisladores 0 en la que habitan sus jueces, o la más opulenta de los adinerados.

No parece ser que el proyecto de la resocialización combine muy bien con sociedades pluralistas. La discusión puede permitir esta pregunta: ¿será que un gitano que roba debe ser resocializado no a su comunidad, sino a la sociedad mayoritaria que no es trashumante, que es disciplinaria, vertical, jerarquizada, o tan solo debe asimilar dentro del contexto de su cultura que está prohibido bajo sanción penal despojar a otros de sus pertenencias? En la primera hipótesis estaríamos violando el derecho a una identidad, a la diferencia, a la pertenencia a una cultura, a través de una decisión judicial y un proceso penitenciario que impone una aculturación. En la segunda, se respeta su pertenencia cultural y se salva un valor que es necesario para la convivencia social que incluye a todas las culturas coexistentes bajo un mismo Estado. Y aún dentro de esa interculturalidad, es pertinente decir que el propio acto desviado que es valorado a partir de los patrones culturales de la sociedad dominante que suele imponer sus valores en los códigos penales, debe permitir una cierta extrapolación en favor del multiculturalismo cotejando los valores de la cultura minoritaria a la que pertenece el infractor. 
No se ve cómo una institución total, pudiera cambiar positivamente seres humanos cuya situación de marginalidad y desigualdad los ha empujado al delito. No es claro, en efecto, que un encierro violento y degradante, que produce sufrimientos devastadores y humillación permanente, pueda convertir a esas personas, en seres respetuosos de las leyes, obedientes de la autoridad, cumplidores de sus deberes. Si alguna lógica hubiera, sería la de devolver los penados a sociedades diferentes, no digamos igualitarias, pero sí que respeten unos mínimos de convivencia y de respeto de la dignidad humana. Esos mínimos no se respetan en las favelas de Rio, en las callampas chilenas, en los ranchos venezolanos, o en las barriadas miserables de tantas ciudades latinoamericanas.

Es cierto que no todo el que se halle en situación básica de privación material deba caer en el delito, pero al menos en América Latina los índices de la delincuencia convencional están muy ligados a razones de supervivencia. En cuanto a la llamada delincuencia de "cuello blanco", ella ha estado ligada a los procesos políticos estructurales de manejo del poder y de acumulación de capital, lo que al final de cuentas reedita la cuestión económica, aunque en sentido opuesto, no en el de la supervivencia sino en el de la ambición y la dominación. En parecido sentido, para el punto de la criminalidad predatoria convencional, Elbert y Balcarce sostienen que,

(...) si bien no existe una relación de causa a efecto entre marginalidad y delito, sería absurdo negar la ligazón que media entre el deterioro social y sus efectos degradantes sobre el conjunto social, predisponiendo los procesos de criminalización. La falta de expectativas y chances de millones de personas las transforman en "mano de obra desocupada" (desesperada) de la que se nutren las organizaciones delictivas de toda clase, ofreciéndoles trabajo estable y bien remunerado, imposible de obtener en mercados laborales de mera supervivencia?

Debió ser en los países de la periferia donde el mito de la resocialización se hubiera revelado como tal, estallando en mil pedazos, ante la abrumadora tasa de reincidencia, la contundente evidencia de que los ilegalismos económicos marcaban el mayor índice en las estadísticas de la criminalidad y de que esos delitos se originaban en personas provenientes de estratos deprimidos de la sociedad sin mayores alternativas de subsistencia; pero no, la dependencia cultural que hemos padecido del saber de los países centrales nos ha impedido ver lo que era más visible a través de nuestras realidades carcelarias en las que ningún programa rehabilitador se lleva a cabo de manera seria, además de lo que sucede en los cinturones de miseria que rodean nuestras nuevas ciudades donde habita la "clientela" habitual de nuestras prisiones.

7 Carlos Elbert/Fabián Balcarce, Exclusión y castigo en la sociedad global, Buenos Aires-Montevideo, Ed. B de F, 2009, p. 112 
Todavía se oyen discursos de plazas públicas, de recintos parlamentarios, cargados de promesas retóricas de resocialización, como si no hubiera rodado el tiempo con la evidencia de su estruendoso fracaso.

¿Cuáles son las cárceles que nos estremecen, que nos hunden en el pesimismo, que truncan la esperanza, que nos hacen exclamar que la resocialización no es más que una utopía? Son las cárceles del hacinamiento y de la violencia. Las cárceles del hacinamiento en que los presos no tienen un mínimo de espacio físico vital, situación que degrada la mayor parte de las condiciones del hábitat carcelario: higiene, salud, seguridad. En sentido extenso, el hacinamiento incide en la alimentación, como quiera que revela la sobrepoblación en las cárceles y en consecuencia, muchas veces implica disminución de las raciones alimenticias. Este hacinamiento deviene en alteración sicológica; el ambiente de la prisión es tenso y uno de los factores que aumenta esa tensión es el de la densidad demográfica. Es un aumento de la presión, de la amenaza. Los internos si bien desarrollan lazos de conexión, también desarrollan actitudes de exclusión y de enfrentamiento, tendiendo a la conformación de grupos de poder, creados para paliar la dureza de su situación. Allí brota la violencia, la de los reclusos entre sí, a la que se suma la que puedan padecer por el riguroso régimen disciplinario, por la misma intolerancia de los guardas y en conjunto por la mezcla de ambas violencias. En el encierro la intolerancia se extrema. Los altos índices de criminalidad dentro de las cárceles hablan por ello.

\section{La cárcel: una institución violenta}

La cárcel ha sido y es en nuestros países una institución violenta. Con ella no se puede pretender reducir el delito, al contrario, con ese tipo de cárcel lo que se garantiza es la reproducción de la criminalidad. El alto nivel de recaída en el delito demuestra esta retroalimentación, pero además la misma delincuencia primaria se acrecienta a partir de los delincuentes egresados de las cárceles, en la medida en que muchos de estos quieren continuar sus "carreras criminales" requiriendo secuaces para constituir bandas o grupos. También el resentimiento producido por un castigo, muchas veces desproporcionado (en especial para la delincuencia convencional económica), refuerzan su ruptura con el sistema, situación que puede despertar lazos de solidaridad por parte de otros excluidos.

El sistema político ejerce su poder intimidatorio, más allá de los fines legales proclamados de la pena, exacerbando la función de prevención general negativa y excediéndose en la función retributiva. El carácter de estas instituciones totales, tales como lo conceptuó el sociólogo Goffman, opera en la vía de la "desestructuración del sí mismo", lo que el criminólogo Wolf trabajara posteriormente como "destrucción de la personalidad". Allí se articula la resistencia de los internos, resistencia a la pérdida 
de su identidad, lo que está en la base del malestar y la crispación penitenciaria, y a partir de allí, de las revueltas carcelarias.

En la práctica la cárcel implementa un régimen intramuros vertical y autoritario, cuya visibilidad hacia el exterior cumple una función de prevención general negativa, mientras que hacia el interior desarrolla una función de prevención especial negativa altamente retributiva. La función de "cobertura ideológica" no es menospreciable en esa praxis de la prisión, que atribuye con exclusividad, la responsabilidad de las ofensas penales a los reclusos, al tiempo que responde a las demandas públicas de seguridad, con políticas crudamente represivas, soslayando las políticas de rehabilitación (educación, trabajo, comunicación, ocupación) y las políticas sociales que deben impartirse sobre todo en los sectores sociales marginalizados.

Existen dos clases de violencia dentro de la prisión: la violencia del sistema sobre los reclusos y la violencia entre estos. Ellas pueden entreverarse. La primera es una violencia que parte de la concepción misma de la prisión como una institución total autoritaria, que debe reprimir, que debe cobrar, que debe vengar. La vindicta no es un sentimiento del pasado en la historia del derecho penal; subsiste hoy en día. Las voces de linchamiento que se escuchan en las calles de las ciudades latinoamericanas, cuando persiguen a un ladrón, son un reflejo de ese deseo. Los funcionarios de la prisión no escapan a él, y a ello deben sumar su natural prevención por el tipo de trabajo que realizan, que implica ciertamente un determinado riesgo, lo que los lleva a enfatizar en su posición dominante. La fuerza, la contundencia, son actitudes adecuadas para ese fin. Otro factor excitante de la violencia lo constituyen los muy severos regímenes disciplinarios, muchas veces aplicados arbitrariamente. En estos casos el vigilante hace de juez y parte. La percepción de injusticia por parte de los internos, por el rigor extremo del castigo dentro del castigo (en celda de aislamiento por periodos prolongados) y por la arbitrariedad de los funcionarios penitenciarios, antes que apaciguar a los internos, los hace más violentos. Aquí hay una reacción si se quiere primitiva de ferocidad.

La aplicación de un régimen disciplinario de manera implacable y excedida puede entenderse en las condiciones de congestión poblacional de las prisiones. La primera obligación de los funcionarios es que los presos no escapen, pero el tipo de reacción extrema solo empeora las cosas, porque entre más violentas y arbitrarias las cárceles, menos se quiere permanecer en ellas. Los funcionarios no suelen tener la mejor preparación profesional. Pero además, los funcionarios son el frente de combate en una confrontación que deciden los políticos para quienes la cárcel no debe implicar mayores gastos, porque los delincuentes antes de merecer alguna atención lo que merecen es castigo y ese castigo debe ser ejemplarizante, debe ser un escarmiento público, de manera que sus electores queden contentos, pensando que se está acabando con el delito y voten nuevamente por ellos. 
La segunda violencia mencionada puede tener un gran estímulo en la mezcla de los internos, mezcla que revela la sinrazón de un sistema que quiere solo almacenar y deshacerse de individuos que considera desechables. A su vez, esto refleja la visión de un sistema penal que totaliza el concepto de delincuente, reduciendo toda conducta desviada contenida en los códigos penales al mismo rotulo: criminal. No distingue mucho este sistema entre un asesino y un dependiente de almacén que se hurta algunos pesos, entre un violador sexual y un fumador de marihuana, entre un secuestrador y un borracho que ocasionalmente golpeó a un contertulio, entre un atracador y un padre de familia incumplido en su obligación alimentaria, entre un energúmeno que en un arrebato golpeó severamente a alguien y un apacible empleado alcanzado en sus compromisos económicos que desfalcó una caja, entre un maniaco abusador y un depresivo que incurrió en alguna omisión penal, entre delincuentes habituales y delincuentes de ocasión, etc. El sistema los arroja a todos dentro de unos muros y allí los revuelven; algunas veces son mal clasificados y separados, dependiendo de la disponibilidad del personal administrativo y científico, pero también muchas veces, de la corrupción que un interno pueda pagar para ser alojado en un mejor patio. Esta mezcla crea situaciones de violencia entre presos que tienden a imponerse, a dominar, y presos débiles aterrorizados, lo que en un espacio cerrado y de tanta tensión, se acentúa hasta la paranoia. Los índices de mortalidad violenta, de lesiones corporales, de suicidios y de atentados contra la libertad sexuales en las prisiones no son bajos.

Estas violencias se pueden mezclar cuando los funcionarios entran en tratos de corrupción con presos o grupos de presos, de manera que plantean mayores tensiones y desequilibrios en la sociedad carcelaria. Esos tratos se realizan generalmente con grupos mafiosos o bandas con algún poder económico, que se enfrentan con otros grupos, o que quieren imponer su dominio en los pabellones de la prisión. Existe una cierta ley de supervivencia en esta dinámica organizativa, por parte de facciones criminales que se reencuentran en la cárcel. A ellas se suman reclusos primíparos o que no han pertenecido a ninguna asociación delictiva, pero que ven en esa adhesión una alternativa de supervivencia o de mejor pasar en prisión. Igual existe una corrupción administrativa que saca partido de las certificaciones de disciplina destinadas a los jueces, de la dispensa de servicios al interior de la prisión que se pueden conceder mejor y más rápido a quien pueda pagar por esa preferencia. La cárcel puede entonces definirse no solo como violenta sino también como corrupta.

\section{El hacinamiento pestilente}

El sobrecupo en las cárceles es endémico y general en los países latinoamericanos; seguramente en la mayoría de los países del mundo, sino en todos, pero para el objeto de reflexión de este trabajo, para América Latina. Una importante investigación 
promovida por las Naciones Unidas para la región nos habla de que el sistema penitenciario de los 18 más grandes países de la región esta sobrepoblado ${ }^{8}$. Entre los años 1999 a 2002 todas las cárceles tenían sobrecupo. Las más altas eran las de República Dominicana, que tenía una población de $256 \%$ de su capacidad programada, $209 \%$ la de Honduras y $167 \%$ la de El Salvador. Las más bajas eran Nicaragua con 104\%, Costa Rica con 110 y Venezuela con 113.

Para el periodo comprendido entre 2005 y 2007, la investigación encontró como las más superpobladas a Bolivia con 207\%, seguida de Brasil con 173 y El Salvador con 162. Hubo esta vez dos cárceles sin sobrecupo: Argentina con el $99 \%$ y Costa Rica con el 99. De resto todas continuaban con superpoblación. Las menos congestionadas de las que tenían sobrepoblación fueron Nicaragua que mantuvo el porcentaje de 104, Venezuela con 115 y Colombia con 117. En un cuadro estadístico sobre los países del Caribe, se estableció que de 12 países solo tres no estaban congestionadas, y entre las que si lo estaban, varias presentaban cifras record de superpoblación, Granada con $394 \%$ y Barbados con 314\%.

Si esta condición de privación de la libertad es grave por las condiciones de hacinamiento que se padecen, lo es mucho más en cuanto las personas recluidas no hayan sido condenadas. Al final de cuentas, quien sí lo está, paga una culpa que se le ha demostrado. Entre los que no tienen condena se encontrarán muchos que serán absueltos deviniendo en injusticia su encierro. La investigación antes mencionada estableció porcentajes alarmantemente altos entre 1977 y 1982 de personas recluidas sin condena; porcentajes hasta de $94 \%$ de población penitenciaria sin condena, con promedio bordeando el 70\%, lo que significa que de cada 100 presos, solo 30 estaban condenados. Lo que se ha dado en llamar casos de condena anticipada. Llegando a nuestros días, la situación ha obtenido una mejoría, el máximo ha sido de 79\%, mientras que el promedio ha sido del $48.4 \%$.

Las causas probables de este sensible mejoramiento las conforman las reformas penales que han fijado límites temporales a la detención preventiva, reformas que obedecen a los discursos críticos de la academia o entidades científicas, de penalistas democráticos y criminólogos críticos, y a los reclamos de movimientos de defensores de los derechos humanos. Esa crítica ha señalado la necesidad de reformas en fenómenos tan extendidos en los sistemas penales latinoamericanos como las penas indeterminadas, la prolongación indefinida de la prisión preventiva y otro tipo de anomalías similares violatorias de garantías constitucionales. Y en gran parte se han cristalizado en reformas. Aquella de disminuir el término máximo de detención preventiva ha sido muy importante, pues no eran extraños los casos de levantamiento

8 Elías Carranza (Coord.), Cárcel y Justicia Penal en América Latina y el Caribe, México, ILANUD, Instituto Raoul Wallemberg de Derechos Humanos y Derecho Humanitario, ASDI, Ed. Siglo XXI, 2009, p. 64 
de la detención preventiva por pena cumplida, lo cual constituía toda una aberración. Así mismo y a efectos del tema que se toca, este límite crea una mayor rotación de la población penitenciaria, contribuyendo a la descongestión tan urgente en las prisiones.

La congestión carcelaria evidencia el carácter custodial y meramente retributivo de las prisiones. A los políticos no les interesa la inversión pública en prisiones. Ellos hacen eco de las demandas sociales de represión. La prisión es solo un silo, una bodega en la que se amontonan los delincuentes; se ha referido de cárceles donde hay que hacer turnos para poder dormir acostado. La congestión de Carandiru (Brasil) reveló no solamente la cruda violencia de la prisión más grande de América Latina, sino una epidemia rampante de sida. En todas las cárceles la congestión es siempre un detonante. En Uruguay, enterado el presidente Tabaré Vásquez del estado deplorable y explosivo de las prisiones, dictó una ley de Humanización y Modernización del Sistema Carcelario, que permitió la liberación de 800 presos; pero la experiencia demostró que el problema es de mucho mayor alcance; no basta una ley coyuntural que rebaje penas 0 acelere la concesión de subrogados penales para liberar un buen número de prisioneros. Eso es importante, más no suficiente y rápidamente será superado. De hecho, leyes coyunturales como esas se expiden en muchos países para celebrar por ejemplo "la visita del Papa", la "llegada de un nuevo milenio" o cualquier onomástico que se nos ocurra, y sin embargo, las cárceles han continuado igual. Es exactamente lo que le sucedió a este presidente, cuando tiempo después un informe de la ONU confirmó uno anterior a aquella ley de que el estado de las prisiones en Uruguay estaba cerca del colapso. Se consignaba en dicho reporte rendido por el relator Manfred Nowak, que había encontrado hasta once personas en una sola celda, que la provisión de agua era tan deficiente que los presos tomaban agua del retrete, que la atención médica era tan difícil que los presos se hacían cortes intencionales en su piel para poder ver al médico, que sus necesidades biológicas las tenían que hacer en botellas, etc. En esas condiciones entregó Tabaré Vásquez las cárceles a su sucesor Mujica. Es que es muy fácil hacer una ley, y muy fácil largar unos presos. Es solo un decreto que se puede ordenar redactarlo a un amanuense en media hora.

\section{Regímenes disciplinarios al límite}

Cuando a un ser humano que ya se halla sumido en una pena -y aquí es válida la expresión en ambos sentidos, pena como privación del bien de la libertad y pena como dolor, como padecimiento- se le amenaza con ahondar el castigo al límite, con reclusión prolongada en celdas de total aislamiento, suspensión de visitas, de recreación, y otras privaciones llevadas al extremo, los efectos contraproducentes del castigo han de ser mayores. Un ser humano que ya padece el rigor del encierro, que es amenazado con esos castigos extremos por "descansar en la cama durante el día" o por "descuido 
en el aseo personal", cuando el solo contacto con los muros y el suelo de la prisión ensucian su vestimenta, no puede estar siendo educado o preparado para la libertad, sino para la sumisión abyecta. Han existido penas de aislamiento celular hasta por un año que no son más que un camino expedito a la locura.

Los regímenes disciplinarios han sido básicamente ese constreñimiento extremo, minucioso, implacable. Gritar está prohibido como si la prisión no fuera un solo grito, que bien pudiera visualizarse con la obra maestra de Munch. Foucault nos habla de esos regímenes en las diversas instituciones disciplinarias:

La minucia de los reglamentos, la mirada puntillosa de las inspecciones, la sujeción a control de las menores partículas de la vida y del cuerpo darán pronto, dentro del marco de la escuela, del cuartel, del hospital o del taller, un contenido laicizado, una racionalidad económica o técnica a este cálculo místico de lo ínfimo y del infinito 9 .

Los extremos de la represión disciplinaria dentro de la cárcel llegan al desconocimiento del principio de legalidad. Hay artículos que han autorizado la analogía in malam partem, como el 296 del código penitenciario colombiano vigente hasta 1993: "Las infracciones cometidas por los condenados, no previstas en los artículos anteriores, serán sancionados en forma análoga a la allí establecida, según la índole y gravedad". La situación se agrava si tenemos presente que los comportamientos sobre los cuales había de operar la comparación analógica, son ambiguos, vagos y subjetivos al extremo. Según el art. 243 del mismo código son sancionables todas las conductas "que atenten contra la moral, el orden o el reglamento interno". Todo en consecuencia, está prohibido. Y al mismo tiempo, todo está permitido para el vigilante, de cara a su contendor: el prisionero. Los reclusos no saben cuáles son las reglas de juego dentro de la prisión. Todo un universo de lo inasible, de lo indecible. Y el juez de esos actos indefinidos es el propio carcelero, juez y parte al mismo tiempo.

La responsabilidad por la situación de las prisiones no es solo de los funcionarios penitenciarios, sino del sistema estatal. Los códigos y las leyes disciplinarias son aprobados por los legisladores o decididos por los gobernantes al más alto nivel. Los guardias constituyen el otro extremo de contacto directo con el infractor, el primer extremo es el de la policía. Los guardias son el músculo de ese Estado encargado de mantener a buen recaudo a los prisioneros. Y puede decirse que en cierta medida los guardias también están prisioneros de la situación, porque dentro de unas condiciones precarias para realizar su trabajo se les exige una responsabilidad mayor de la que debieran. Una de esas condiciones es la situación de desventaja por el número de funcionarios en relación con el número de internos que tienen que cuidar. Eso los empuja muchas veces, a ser más violentos, en la medida en que responden por la 
seguridad de la prisión, y dada la correlación de fuerzas con los internos, pueden actuar temerosos de ser desbordados por ellos en caso de protestas y revueltas.

La investigación auspiciada por el ILANUD sobre cárcel y justicia penal en América Latina y el Caribe, reveló que en la mayoría de países se rompe esa proporción. En países como Panamá, Perú, Ecuador, Venezuela, la relación es de diez a uno, cuando lo óptimo es que no pase de tres. Solo Argentina Y México se hallan dentro de esa ratio, aunque con relación a cárceles federales, sin contar con las prisiones estatales -no hubo remisión de datos- que son la mayoría. En cambio en Europa, la generalidad de países se mantiene dentro de ese tope, salvo España que tiene una ratio de 3.5. ${ }^{10}$ Esta proporción de funcionarios podría parecer muy alta, pero teniendo en cuenta que es por turnos, la realidad de la ratio es de 12 a uno, para las cárceles que tengan relación básica de tres a uno. En ese orden de ideas, Panamá que tiene la relación máxima dentro de la investigación del ILANUD, de 18.4 por uno, tendrá una relación en tiempo real de 73.6 a uno, lo que evidencia la dificultad y la sobrecarga del funcionario de vigilancia.

Desde luego que debe existir un derecho disciplinario al interior de la prisión; La sociedad carcelaria como toda sociedad requiere de sus reglas de cohabitación. Por supuesto, como es un encierro hacinado de seres humanos crispados, en seria tensión con una sociedad, esas reglas deben ser más rigurosas. Y como las cárceles solamente han perseguido encerrar, almacenar seres humanos, los regímenes disciplinarios han estado dirigidos básicamente a asegurar el orden y la disciplina; de allí que sean proclives a la arbitrariedad y al abuso en su aplicación. Es esto lo que se debe erradicar si se aspira a egresar un penado menos envenenado contra la sociedad, y con alguna disposición de entendimiento con ella.

\section{Privatización de las cárceles}

La política neoliberal en su voracidad económica y en su falta de vocación humanística quiere someterlo todo a las leyes del mercado, hasta la libertad humana, no le ha bastado con echarle mano a las empresas de servicios públicos sino que ahora estira sus tentáculos sobre la libertad de los seres humanos. ¿Qué puede ser más rentable que vender agua, energía, servicio de recolección de basuras, telefonía?, y ahora, ¿Qué puede ser más contradictorio entre el Estado como depositario del interés general, garante principal de los derechos fundamentales y una empresa privada más, un negociante más, movido por su interés particular de hacer ganancia, con poca o ninguna vocación de justicia, de realización y salvaguarda de esos derechos básicos? Lo que le interesa a una empresa de estas, es generar el mayor lucro, para así

10 Datos del Consejo de Europa, Penological Information Bulletin, número 25, diciembre de 2003. 
responder a sus socios, y para, cotizar en la Bolsa con los mayores valores. Correction Corporation of America (CCA) es una de las empresas que mejor cotiza en la Bolsa de Nueva York. Para ese efecto, la señalada empresa ha degradado la atención médica, la alimentación, el aseo; eliminado torres de vigilancia, reducido personal de centinelas, paga menores sueldos a los vigilantes, convierte a los guardias en accionistas de la empresa, con lo cual no le paga prestaciones sociales ni tienen derecho a pensión alguna -ya se sabe que esto es parte del libreto neoliberal-.

Cuando hablábamos en el pasado de "clientela" del sistema penal o de "clientela" de las prisiones, lo hacíamos en un sentido metafórico, ahora no; con la privatización de las cárceles se trata de una cruda realidad. Estas empresas de la guarda, administración y custodia de seres humanos, tienen que propender porque haya una suficiente clientela para su negocio. Tan solo por eso, el reporte que puedan hacer del comportamiento de los reclusos, de cara a los subrogados y beneficios penales de libertad, será totalmente interesado para favorecer la permanencia del cliente en el mercado; léase: prisión. Igualmente estas empresas están interesadas en el ensanchamiento del mercado. El Estado por su parte, debe procurar un mínimo de clientes para hacer rentables las cárceles a la iniciativa privada. ¿Deberá entonces arreciar las capturas cuando sus contratistas de prisiones presionen por ese mínimo?

La respuesta nos la ayuda a dar el diario The Guardian de Gran Bretaña del 3 de marzo de 2009 en el que se reseña que dos jueces fueron condenados en Pensilvania (Estados Unidos), por enviar a prisión a cerca de 2.000 adolescentes a cambio de sobornos. Los jueces Ciavarella y Conahan recibieron 2.600.000 dólares de la empresa Mid Atlantic Youth Services Corp., por ayudarles a llenar sus cárceles. Entre sus condenados está una chica de 15 años sentenciada a tres meses por crear una página web ridiculizando a su asistente principal del colegio. Otra de 13 años fue enviada a una prisión para adolescentes por entrar sin permiso a un edificio vacío. Otra de 14 años fue condenada a once meses por cachetearse con una compañera escolar. Al lado de estos fraudes hay otros como el de algunas cárceles pasando facturas por presos que no tienen.

Pero esta corrupción no es solamente negocio de jueces. El ejecutivo también recibe, aunque trata de enmascararlo como lobby. En Estados Unidos se descubrió que en el 2007, la C.C.A. gastó 2.5 millones de dólares con representantes del gobierno federal abogando por las cárceles privadas. Otra empresa, el grupo GEO reconoció haber hecho contribuciones a los políticos por tres cuartos de millón de dólares. Durante las elecciones de 2002 y de 2004, empresas carcelarias hicieron contribuciones por valor de 3.3 millones de dólares a las campañas de candidatos y de partidos políticos estatales ${ }^{11}$.

11 The Institute On Money In State Politics, Policy Lockdown: Prison Interests Court Political Players, www. followthemoney.org, abril de 2006. 
Ha sido en Estados Unidos donde esta política neoliberal ha arraigado más prontamente. Los efectos adversos sobre los derechos humanos ya se dejan ver: brutalidad en el trato, disminución de la calidad de los servicios. Nada de dignidad humana, de individualización en la ejecución de la pena, de reintegración. Cruda actividad de disciplinamiento y sometimiento. El Estado de Carolina del Sur no renovó el contrato con la CCA cuando constató que los jóvenes eran amarrados y encadenados. Los inspectores de la British Prison Officers Association, en visita a la cárcel de Silverdale (Tennesse) administrada por la misma CCA, observaron centenares de inmigrantes encerrados hasta por 23 horas diarias en una especie de almacenes. En una prisión juvenil de Tullalah (Luisiana), gestionada por Trans-American Development Associates, se constató que numerosos jóvenes - muchos de ellos enfermos mentalesfueron golpeados resultando con lesiones de tímpanos perforados, narices y quijadas fracturadas. Los que no obedecieran cabalmente las órdenes eran encerrados en celdas de aislamiento durante semanas o se les ampliaban arbitrariamente sus sentencias. ${ }^{12}$

Bronstein relaciona abusos sexuales y maltratos de la firma Wackenhut Corrections Corporation, en Austín (Texas), donde la cárcel fue multada con 625.000 dólares; en Jena (Louisiana) el centro de reclusión tuvo que ser retomado por el Estado. En Dallas (Texas) dos empleados de dicha empresa se declararon culpables de asalto sexual contra muchachas encarceladas en el Condado Coke para delincuentes juveniles. En Colorado, el Estado cerró la prisión juvenil operada por Rebound Corporation después del suicidio de un enfermo mental de 14 años, del cual resultó una investigación que reveló casos de abuso físico y sexual institucionalizados. ${ }^{13}$

Otra gran transnacional norteamericana de las prisiones es la Wackenhut Corrections Corporations. Tiene contratos en Sudáfrica, Australia, un centro de detención de inmigrantes en el Reino Unido y un contrato de custodia en el Centro de Detención de Inmigrantes, nada menos que en Guantánamo. Y por si fuera poco, la participación de estas empresas en la industria de la represión, el gobierno de U.S.A. entregó a otra empresa norteamericana el montaje y la puesta en funcionamiento de la ignominiosa cárcel de Abu Ghraib en Irak.

Nathan refiere que la privatización de las cárceles en Estados Unidos es iniciada por empresarios conectados con el Partido Republicano o con el complejo militar e industrial de ese país, que estaban ansiosos por explorar la nueva ola de privatización de bienes y servicios del Estado, política liderada académicamente por los economistas

12 Fox Butterfeled, "Hard time profits at a juvenile prison come with a chilling cost" en The New York Times, 15 de julio de 1.998

13 Alvin J. Bronstein, "Opinión y debate, privatización de prisiones", en www.chhdf.org.mx/index. php?id=dfeabro4priva, México, página de la Comisión de Derechos Humanos del Distrito Federal. 
de la Escuela de Chicago, la que recibió impulsos definitivos con la administración Reagan y por la del Reino Unido de Margaret Thatcher.

Al lado del modelo norteamericano en el que se contrata todo a la iniciativa privada, está el llamado modelo francés de semiprivatización, en el que el Estado se reserva la custodia. Algunos países latinoamericanos se han orientado por ese modelo. El gobierno argentino de Carlos Menen aprobó la ley 24.660 que establece que "Cuando medien fundadas razones que justifiquen la medida, el Estado podrá disponer la privatización de servicios de los establecimientos carcelarios y de ejecución de la pena, con excepción de las funciones directivas, el registro y documentación judicial del interno, el tratamiento y lo directamente referido a la custodia y la seguridad de procesados o condenados." En Brasil varios Estados, entre ellos Paraná, Bahía, Minas Gerais, también se han orientado por ese modelo, reservándose la custodia y la seguridad externa de la cárcel. Chile lo programó para diez cárceles semiprivadas.

En América latina han estado penetrando empresas concesionarias de servicios en las prisiones. La firma francesa Sodexo tiene contratos penitenciarios en Chile, Argentina, Brasil, Colombia, Costa Rica y Panamá. También se plantea acudir a los contratos de leasing, mediante los cuales las cárceles pueden ser adquiridas por el arrendatario estatal, luego de pagar cánones en periodos de entre 20 a 30 años. Muchos gobiernos latinoamericanos comienzan a hipotecarse, alegando falta de fondos, comprometiéndose por años a pagar el precio de jugosos contratos para la construcción y gestión de cárceles por consorcios privados. Como se ve, el futuro no es muy alentador; vendidas las empresas básicas productivas de los Estados (energía, agua, telefonía, servicios de aseo, etc.), y pagando altas amortizaciones de préstamos de manera continua, no hay más alternativa que aumentar impuestos y eliminar las pocas políticas sociales que aún existen.

Si los derechos fundamentales están saliendo mal librados, tampoco la finalidad económica de ahorro se cumple en las experiencias de privatización. En Sudáfrica, con asesoría del Reino Unido, el gobierno firmó contratos para dos cárceles de 3.024 camas, que costaron el $50 \%$ de todo el presupuesto del sistema penitenciario. Ante semejante exabrupto el gobierno ha tratado infructuosamente de renegociar los contratos. Ni más faltaba que con semejante desproporción -solo 2 cárceles se llevan el 50\%-, las empresas fueran a aceptar reducción de sus ganancias, por abusivas y leoninas que sean ${ }^{14}$.

En Chile, el senador Alejandro Navarro criticó los costos de las cárceles de Concepción y Antofagasta como "un escándalo", anotando que para la primera se convino un precio de 21.5 millones de dólares, pero luego en la ejecución de la obra se

14 Stephen Nathan, "Privatización de la prisión: acontecimientos y temas internacionales y sus implicaciones en América Latina", en Cárcel y justicia penal en América Latina y el Caribe, México, Ed. Siglo XXI, llanud, Asdi, Raoul Wallemberg Institute, 2009, pp. 298 y 299. 
incrementó a 65 millones, sin que se hubiera siquiera terminado ${ }^{15}$. De otra parte, se han presentado protestas entre los reclusos por la alimentación y por la discriminación en las visitas, si bien se reconoce una reducción en el hacinamiento ${ }^{16}$.

En la propia Francia, la Cour de Comptes (contraloría nacional) encontró que las cárceles semiprivadas costaban entre $8.5 \%$ y $50 \%$ más que las cárceles públicas y se declararon "atónitos" por el hecho de que el gobierno hubiera usado este modelo para sus nuevas 18 prisiones. No deberían 'sorprenderse' tanto los auditores del Estado francés, si tuvieran en cuenta que los procesos de desmonte del Estado del Bienestar en el proyecto neoliberal no se hacen solamente por una pretendida mayor capacidad de gestión del sector privado, sino por una política global de favorecimiento a las transnacionales dentro de procesos políticos multimillonarios que muchas veces pagan la respectiva 'comisión' a los gobernantes. Esta es, por supuesto, una criminalidad que fácilmente eludirá el cedazo de la ley penal, encubierta en elaborados discursos de política económica y políticas fiscales.

Reiteremos que la privatización no ha incidido positivamente en el nivel de reincidencia. Estados Unidos tiene la más alta tasa de presos del mundo y el Reino Unido, la segunda más alta de Europa, siendo los dos países, los abanderados y empresarios de la privatización. En cambio Irlanda tiene una tasa que es la mitad de su vecino británico, y lo mismo Canadá en relación con Estados Unidos, que es un séptimo de la de su poderoso vecino, teniendo Irlanda y Canadá sistemas públicos penitenciarios eficientes. Finalmente ha de expresarse la duda sobre la constitucionalidad de esta política de privatización en la justicia. Las constituciones latinoamericanas generalmente consagran la justicia como una función pública, como un poder del Estado, y siendo la ejecución penal expresión esencial del ius puniendi, mal se puede aceptar que quede en manos de particulares. El sistema penal está comprendido no solo por las leyes penales y por el conjunto de policías, fiscales, jueces, que las aplican, sino por el sistema penitenciario que ejecuta las sentencias de privación de libertad. Dejar en manos de mercaderes privados la ejecución del castigo es retroceder en la historia a estadios privados de reacción social y contrariar principios éticos y jurídicos de humanidad y garantismo.

\section{Cárceles dignas y socializadas con la comunidad}

Las cárceles no deben ser una ínsula. No deben ser más esa fortaleza inexpugnable, arcana, donde olvidada del mundo habita una sociedad de excluidos. Esas fortalezas deben tender sus puentes levadizos y comunicar la sociedad carcelaria con la sociedad mayor. Si se pretende reintegrar no se lo puede hacer en el aislamiento total y el olvido.

15 Ibíd., p. 302

$16 \quad$ Ibíd., p. 302 
Por un lado, los penados deben ver algún horizonte y por el otro, la sociedad debe tener a la vista las consecuencias de lo que en gran parte sucede por su injusticia social. La sociedad no puede desentenderse de esa corresponsabilidad que tiene en el delito, mucho más, en sociedades de tan abismales desigualdades como las de América Latina. La cárcel debe integrarse a su medio, a su comunidad. Debe estar comunicada con su entorno social. Debe haber por ejemplo vinculación del sistema educativo con las cárceles: Las facultades de derecho, de sicología, de medicina, entre otras, pueden tener consultorios en los establecimientos carcelarios, y en convenio con el Estado validar pasantías, tesis, prácticas de sus estudiantes próximos a graduación; también a partir de los programas de educación desescolarizada, universitarios y técnicos. Eventualmente conceder permisos de estudio a internos de cárceles de mediana y mínima seguridad que se encuentren en el último tercio de su privación efectiva de la libertad. Los grupos de voluntariado ya se hacen presentes en cárceles de muchos países, para hacer compañía por una tarde, conversando, compartiendo juegos de mesa, dictando charlas, etc. Un programa de gran alcance puede ser el deportivo, en el que se fomente el deporte y se programen además encuentros entre equipos externos y equipos de confinados. Se puede institucionalizar ferias que exhiban y ofrezcan comercialmente los productos de la creatividad y el trabajo de los internos. En fin, hay que dotar de un contenido más noble el tiempo en prisión. Ello no diluye el castigo. El encierro es encierro, así se pague en una mansión. Lo importante es disminuir el dolor y la vejación continua de nuestras cárceles actuales y si ello apareja la reducción de la reincidencia, como podemos vaticinar que sucedería sin el "envenenamiento" de los reclusos, será un valor agregado viejamente anhelado por la sociedad.

En ese sentido, las cárceles no deben ser feudos o espacios vedados a la mirada y al control exterior estatal y ciudadano. Diversos funcionarios del Estado tienen competencia para ejercer ese control: jueces de control de penas, defensores públicos, procuradurías, Fiscalía. Eventualmente la sociedad puede coadyuvar en el control, cuando a partir de su comunicación con la cárcel detecte anomalías que puede denunciar. Las cárceles deben integrarse a la comunidad, articularse a la sociedad; los presos deben experimentar todavía un sentimiento de pertenencia a ella -la comunidad-. En cambio de privatizarse, las cárceles deben mantenerse en el campo de lo público, pero con una interacción decisiva de la sociedad. Atrás tocamos el tema de la rapacidad neoliberal echándole mano a las cárceles en jugosos contratos, que obviamente, para seguir la lógica del capital, implica acentuar -aún más- las condiciones infrahumanas de la prisión. Nuevos feudos, nuevas fortalezas, en manos de mercaderes de la represión.

Para que las cárceles puedan ligarse a la comunidad se necesita que sean más manejables, que no sean del tipo de las mega cárceles que se advierten ahora en auge. Conservar las cárceles en un tamaño medio que permita que la sociedad 
carcelaria pueda interactuar, entre sí y con el exterior; las grandes cárceles producen problemas mayores de seguridad. Debe aprovecharse esta política y separar reclusos, de diferentes niveles de seguridad, en distintas cárceles, de manera que entre menor exigencia de seguridad, mayores avances en socialización. Mezclados todos en las mismas prisiones, las reglas draconianas de seguridad son las mismas para un violador que para un ladrón doméstico. Esta aspiración de una cárcel vinculada a su comunidad, implica que no deben construirse en lugares geográficamente alejadas de ella. Esto tiene un impacto negativo en la psiquis del recluso y puede incidir en la tasa de suicidios.

La jurisdicción de ejecución de penas es clave en el panorama de control del estado de cosas dentro de la prisión. La garantía judicial debe acompañar al ciudadano hasta el último minuto en que purgue su pena. En la ejecución penal naufragan generalmente los fines declarados de la pena, que ceden su lugar a los fines latentes, dotados de muy diversos contenidos: venganza, sometimiento, ejemplarización, cobertura ideológica, etc. La mayoría de las sentencias judiciales, muchas veces imbuidas de principios garantistas, se estrellan con la inhumanidad de la praxis penitenciaria. Estos jueces penales especializados deben decidir o conceptuar sobre los condenados para efectos de su ubicación intramural, decidir las libertades que correspondan a los subrogados penales cuando hayan cumplido parte principal de la pena ${ }^{17}$, deben ser instancia de apelación para el derecho interno disciplinario, cuando la ley taxativamente lo prevea de manera que no haga inútil la reacción rápida que se pueda exigir en ciertas situaciones. También han de decidir el punto de las redenciones de pena (trabajo, estudio, enseñanza, creatividad), sobre las aplicaciones del principio de favorabilidad que incidan en la pena, y todas aquellas generales que ya se le asignan a esta jurisdicción en los países de la región como la de tomar todas las decisiones necesarias para que las sentencias ejecutoriadas que impongan sanciones penales se cumplan y las de aprobar ciertas solicitudes de los funcionarios de prisiones para efectos de beneficios administrativos que supongan modificación en las condiciones de ejecución o en el tiempo de las penas. Y como marco de todas estas responsabilidades el juez de ejecución penal debe velar por la vigencia de los derechos humanos.

Los organismos legales de control, defensoría pública, procuraduría, fiscalía, dentro de las competencias legales que tienen, deben velar por la civilidad de la prisión, atendiendo las quejas y las denuncias con la conciencia de que quienes las interponen constituyen un grupo vulnerable por su situación de confinamiento. Para ello deben tener una sede dentro de la prisión que podría ser para la defensoría pública (Defensor del Pueblo), de modo que el control pueda ser directo. No se puede dejar que

17 Los subrogados iniciales, que se pueden reconocer una vez dictada la sentencia, deben ser decididos por el juez de conocimiento, como quiera que es quien tiene la facultad de decidir de fondo sobre el alcance de la sentencia, y además porque es quien para el momento tiene el conocimiento adecuado del caso y del condenado. 
la posibilidad de quejarse, sea solamente ante las mismas autoridades penitenciarias, quienes pueden ser parte interesada en el asunto. El reo debe tener la posibilidad de dirigirse tanto a ese defensor, y por su intermedio a la Fiscalía, a los jueces penales y a la procuraduría. Y por supuesto a los mismos funcionarios de la prisión que eventualmente puedan resolver el caso.

\section{Educación: una deuda socio-cultural}

La educación que se pueda impartir en las cárceles no debe ser la que pretenda moldear al recluso como miembro dócil de una sociedad; debe perseguir más bien el desarrollo de su personalidad, dotándolo de habilidades y competencias para ser miembro de una sociedad libre, ilustrándolo sobre sus derechos y obligaciones como ciudadano. Si un reo al ingresar a la cárcel no sabe leer ni escribir, lo mínimo que debe pasar es que el Estado en cumplimiento de una obligación constitucional de permitir el acceso cultural a todos los ciudadanos, brinde a ese interno ese aprendizaje; esa es una deuda social que el Estado debe pagar. Si el penado debe pagar su deuda con la sociedad por la violación de los derechos de otros, el Estado y la sociedad deben pagar la suya cuando han marginado al desviado del acceso a los bienes culturales. Gran parte de la comunidad carcelaria de nuestros países latinoamericanos proviene de los cinturones de miseria de las ciudades en los que la escolaridad es de bajo nivel. Esa educación básica se puede impartir en buena medida con métodos desescolarizados, apoyados en adecuadas ayudas pedagógicas (audiovisuales, bibliográficas, etc.).

Cuando hablamos de educación al interior de la prisión, no nos referimos a una educación de "lavado cerebral", de sometimiento, de internalización de valores dominantes, sino de una educación que por un lado forme al interno en el concepto de sujeto de derecho y como tal, sujeto de obligaciones. Esto implica no que se le hable solamente de sus derechos, sino también de los derechos ajenos, que él violó, cuando debió respetarlos. Pero el recluso debe saber también, y con ellos los funcionarios de prisiones, que el penado sigue siendo sujeto de derechos fundamentales, que la pena privativa de la libertad solamente restringe su libertad de locomoción en la medida en que lo prevea la ley y los derechos que de la restricción de aquella se desprendan. Por eso la educación debe ser voluntaria. Si el penado prefiere el ocio es su elección. De otro lado, educación es capacitación para dotar de habilidades, destrezas, competencias, para que el egresado carcelario pueda eventualmente ejercer un oficio dentro de la prisión, 0 al menos, para enfrentar su difícil etapa de postpenado. Incluso esa formación vocacional puede orientarse hacia el trabajo independiente (artesanal, microempresarial, etc.). Hay suficientes programas al exterior, de apoyo a estas líneas económicas que se pudieran articular con la prisión. En cuanto a lo educativo, existen entidades educativas a distancia que pueden ofrecer sus programas a las cárceles; más si son entidades de educación pública. Habrá reclusos que tengan determinada 
formación técnica o profesional, con lo cual podrán participar como docentes, debiendo obtener por ello la respectiva redención de pena.

En América Latina existen muchas comunidades indígenas que como etnias discriminadas, suelen ser de las más criminalizadas; con relación a ellos debe actuarse muy celosamente en la protección de sus culturas, de manera que los programas de educación no implique extender y hasta intensificar procesos de aculturación. En este aspecto, hay que llamar particularmente la atención sobre la injerencia de diversas iglesias y sectas que pueden aprovecharse de esa situación de vulnerabilidad para hacer su proselitismo religioso con la aprobación de las autoridades penitenciarias.

También hay discriminación en el caso de las mujeres reclusas, cuando se les educa dentro de la prisión con programas que refuerzan roles sexistas domésticos. Antony nos habla de la ley de ejecución de penas bolivianas en la que se complementa los programas de enseñanza con educación y prácticas de "estudios de materias propias del hogar" (art. 37) ${ }^{18}$. Aunque ese tipo de enseñanza no es censurable de suyo, lo que se crítica es que esté únicamente dirigida a las cárceles de mujeres.

Una política penitenciaria que aspire a disminuir los índices de recaída debe encarar los procesos de subculturación que sufren los presos, por parte de los grupos de criminales más fuertes, quienes tratan de imponer su orden dentro de la prisión y de reclutar nuevos individuos para sus salidas futuras. Esos procesos se basan en la violencia de aquellos grupos fuertes, en el prestigio de esos clanes o el de sus líderes, y en la propia violencia y arbitrariedad de las autoridades que lanzan a los presos débiles en los brazos de los clanes subculturales. Aquí es donde debe articularse el componente educativo de una política de no-reincidencia, para acentuar la valoración de una cultura de respeto de los derechos ajenos y contrarrestar así la cultura delincuencial que se propaga proactivamente en la prisión $n^{19}$. Finalmente hay que aceptar que sí se verifica en las cárceles un proceso de integración, pero en sentido inverso al esperado, hacia los grupos y subculturas delincuenciales -bandas, mafias- en las que los delincuentes primarios encuentran identidad, acogida y hasta perspectivas de supervivencia económica.

Un programa de educación en la cárcel se plantea no como un proceso de reeducación, que encaja en su seno un proyecto de sometimiento, en la medida en que vuelve a educar para homogenizar socialmente; no para preparar para la libertad, entendiendo ésta como la facultad de actuar responsablemente sin atropellar los derechos de los demás; en ningún caso como la posibilidad de actuar ilimitadamente.

18 Carmen Antony García, Las mujeres confinadas, Santiago de Chile, Editorial Jurídica de Chile, Santiago de Chile, 2000, p. 77.

19 Alessadro Baratta, Criminología Crítica y Crítica del Derecho Penal, México, Ed. Siglo XXI, 1986. 


\section{El trabajo: la deuda económico-social}

Una política penitenciaria y por ende, una política criminal, deben partir de la premisa de que hay déficit de empleos en el mercado de trabajo, que empuja algunos sectores sociales a la marginalidad del sistema de producción. Esa marginalidad suele derivar al crescendo de la violencia, al aumento de las tensiones sociales, a la desviación criminal. Ni siquiera se trata de mantener un "ejército de reserva" laboral en los países periféricos, pues las cifras desbordan la perspectiva de un manejo a discreción de la mano de obra, y lo que sobreviene es un caos social violento, que dudamos nadie quiera como consecuencia de una política o designio de una cierta organización social, caos que el sistema decide afrontar con mayor represión y expansionismo penal. No pretendemos caer en el esquema fácil de un reduccionismo económico, pero si resaltar que el tema del trabajo se encuentra presente en el tema de la cuestión penal. Una política penitenciaria debe tener en consecuencia, un programa de cara a esa falencia, un programa sin pretensiones grandilocuentes de regeneración y resocialización, sino con criterios si se quiere pragmáticos de ofrecer a víctimas de la discriminación social que son la mayoría de los delincuentes convencionales, alternativas de desempeño laboral dentro de la prisión y fuera de ella, en el futuro postpenitenciario. Por ese criterio pragmático, también se apunta más a un trabajo independiente, dadas las condiciones de marginalidad en que viven los que caen en las cárceles y la mayor distancia social que sobre ellos se acrecentará como ex-convictos, una vez egresen de la cárcel.

Un trabajo dentro de la prisión implica posibilidad de atender el sostenimiento de la familia, un ahorro para el futuro en libertad, una fuente para la restauración a la víctima por la lesión ocasionada. Por supuesto, jamás se prohijará un trabajo en favor de empresas que desconozcan los mínimos derechos laborales. Eso ha sucedido y sucede en cárceles latinoamericanas y constituye una infamia, un abuso de la condición de postración y de vulnerabilidad de los confinados ${ }^{20}$. El trabajo durante la ejecución penal puede considerarse para ser cumplido exteriormente, después de determinado cumplimiento de la pena -dos terceras partes por ejemplo-. Desde luego, que el tipo de trabajo debe dejar a salvo la dignidad humana; nada de trabajos que involucren pornografía o actividades de prostitución, por ejemplo.

A despecho de las críticas contra la prisión y sus programas de trabajo, estimamos que partiendo de la idea de que es voluntario, de que debe respetar la dignidad humana y no darse en condiciones de sobrexplotación, es una necesidad de cara a aquellos factores familiares, restaurativos y de previsión del futuro

20 Antony García lo refiere para el caso de cárceles de mujeres en México, a las que se les burla el 30\% de su salario que supuestamente se destina a sus familias, las que no lo reciben nunca. En Las mujeres confinadas, cit. p. 75 . 
postcarcelario. Sobre esto último los Estados latinoamericanos no tienen política alguna y la recaída es el puerto más seguro a donde llegar. Es cierto que la sociedad disciplinaria que nos revelara Foucault irradia su influencia en estas instituciones totales, y dentro de ellas los programas educativos están básicamente dirigidos para hacerlos "dóciles y útiles" a los penados, pero mientras se nos ocurre algo mejor que la cárcel, debemos paliar su crueldad, ofrecer a los internos posibilidades de ocupación y de cierta realización profesional. Con esa oferta, de trabajo y de educación, hecha libremente y sin fines de sojuzgamiento, la sociedad puede en parte compensar los derechos que le ha negado a gran parte de la población que ha caído en desgracia por la comisión de un acto criminal. Si quienes ingresan a la cárcel han sido, por el contrario, privilegiados, que han tenido acceso a los bienes materiales y culturales de la sociedad, pues tendrán también la oportunidad de dar, restaurando los perjuicios, colaborando en trabajos colectivos con la comunidad, enseñando, si tuvieran la aptitud para hacerlo, etc. Las sociedades carcelarias necesitan ese empeño colectivo, que puede vehicular un proceso de integración basado en la solidaridad y en la convivencia pacífica. Si hay internos que prefieran el ocio, están en su legítimo derecho. El ocio no solamente puede ser "la madre de todos los vicios", también puede ser una fuente de creatividad, de encuentro colectivo, de introspección espiritual. La sociedad moderna ha estigmatizado el ocio siguiendo un criterio utilitarista, que muchas veces teme al ocio como inspirador de la crítica y la protesta social. Prefiere mantener a los individuos en sus rutinas, procedimientos y disciplinas, obedeciendo técnicas y mecánicas del poder. No hay preguntas, no hay cuestionamientos, solo aceptación y adhesión a la coerción disciplinaria.

Claro, este planteamiento de la necesidad del trabajo poco puede sostenerse como un derecho, cuando en la práctica es un privilegio. Bien podría replicarse en lo iluso de la propuesta, con toda esa congestión carcelaria en la que muchas veces no hay espacio ni para dormir decentemente. Bueno, esto supone indispensablemente el aumento de los espacios, de los presupuestos, no en niveles óptimos, porque sabemos de la precariedad de nuestros países. Pero además hay medidas que no cuestan mucho: reducción de las conductas criminalizadas, políticas alternativas a la prisión, clasificación adecuada de los internos para reducción de la tensión por razones de seguridad -se daría prioridad a la delincuencia convencional en cárceles de mediana y mínima seguridad-, trabajo en empresas como lo hemos propuesto, con algún estímulo tributario (no a costas del salario de los internos), trabajos de interés comunitario, totalmente voluntario y dignificante ${ }^{21}$, políticas autogestionarias en las cárceles, que no comprometan su seguridad obviamente, etc.

21 ¿Qué tal pensar en trabajos de reforestación (siembra de árboles) en cuencas erosionadas, de jardinería en zonas verdes? Claro, esto es factible para penados que estén a punto de culminar sus penas; podría decirse que les falte un quinto de ella, de manera que no sea 'negocio' para ellos, la fuga. 
Concluyendo, hay que decir que la política penitenciaria actual en América Latina es fantasmagórica; no existe en realidad una política sino una inercia que viene desde los albores de las Repúblicas, inercia de encierro copiada de Europa, con discursos incluidos; inercia de prácticas, rutinas, disciplinas, técnicas de represión y disciplinamiento; pero acá se agrava la cuestión, por el estado de subdesarrollo de las fuerzas productivas, por las mayores desigualdades sociales y por la precariedad de nuestros presupuestos. Pero más allá de todo esto, por la precariedad mental y ética de nuestros gobernantes, que suponen la cárcel como una "nave de locos" -a la manera de la figura medieval y la célebre pintura del Bosco- que haya que abandonar a la deriva.

\section{Bibliografía}

Antony García, Carmen, Las mujeres confinadas, Santiago de Chile, Editorial Jurídica de Chile, 2000.

Baratta, Alessandro, Criminología Crítica y Crítica del Derecho Penal, México, Ed. Siglo XXI, 1986.

Bronstein, Alvin J., "Opinión y debate, privatización de prisiones", en www.cdhdf.org. mx/index.php?id=dfeabr04priva, página de la Comisión de Derechos Humanos del Distrito Federal, México.

ButTeRFIELD, Fox, "Hard time profits at a juvenile prison come with a chilling cost" en The New York Times, 15 de julio de 1.998

Carranza, Elías (Coord.), Cárcel y Justicia Penal en América Latina y el Caribe, México, ILANUD, Instituto Raoul Wallemberg de Derechos Humanos y Derecho Humanitario, ASDI, Ed. Siglo XXI, 2009.

Christie, NiLs, La industria del control del delito, Buenos Aires, Editores del Puerto s.r.l., 1993.

Datos del Consejo de Europa, Penological Information Bulletin, número 25, diciembre de 2003.

Elbert, Carlos/Balcarce, Fabián, Exclusión y castigo en la sociedad global, Buenos AiresMontevideo, Ed. B de F, 2009.

Foucault, Michel, Vigilar y Castigar, México, Ed. Siglo XXI, 1976, p.144.

Nathan, Stephen, "Privatización de la prisión: acontecimientos y temas internacionales y sus implicaciones en América Latina", en Cárcel y justicia penal en América Latina

y el Caribe, México, Ed. Siglo XXI, Ilanud, Asdi, Raoul Wallemberg Institute, 2009.

The Institute On Money In State Politics, Policy Lockdown: Prison Interests Court Political

Players, www.followthemoney.org, abril de 2006. 